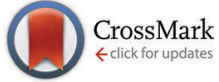

Cite this: Phys. Chem. Chem. Phys., 2016, 18, 24631

Received 30th May 2016, Accepted 15th August 2016

DOI: $10.1039 / c 6 c p 03723 b$

www.rsc.org/pccp

\section{A DFT study on dihydropyrazine annulated linear polyacenes: aromaticity, stability and HOMO-LUMO energy modulation $\dagger$}

\begin{abstract}
Ramachandran Rakhi and Cherumuttathu H. Suresh*
Linear polyacenes (LPAs) beyond pentacene are highly unstable and their application potential in the optoelectronics field is very limited. On the basis of theoretical studies at the M06L/6-311++G(d,p) level of DFT, we show that annulating dihydropyrazine units to LPA cores can yield large LPA mimics. This strategy enhances the aromaticity of the LPA core and also provides a way to modulate the HOMOLUMO energy gap by choosing an appropriate LPA core and extending dihydropyrazine annulation. The study is conducted for LPA mimics containing up to six dihydropyrazine units annulated to benzene $\left(p B_{1}-p B_{6}\right)$, naphthalene $\left(\mathrm{pN}_{1}-\mathrm{pN}_{6}\right)$, anthracene $\left(\mathrm{pA}_{1}-\mathrm{pA}_{6}\right)$ and tetracene $\left(p T_{1}-p T_{6}\right)$ cores. The longest of them $\mathrm{pT}_{6}$ contains 34 linearly connected six-membered rings. The dehydrogenation energy $\left(E_{\mathrm{dh}}\right)$ of the $\mathrm{N}$-heterocycles of the LPA mimics showed endothermic character and indicated their higher stability than dehydrogenated $\mathrm{N}$-heteroacenes. The total $E_{\mathrm{dh}}\left(\Sigma E_{\mathrm{dh}}\right)$ is proportional to the increase in the number of heterocycles and the increase in the size of the LPA core. The aromaticity of individual rings of all the LPA mimics is assessed on the basis of the harmonic oscillator model of aromaticity (HOMA) and nucleus independent chemical shift (NICS) parameters. Both parameters showed strong linear correlation with $\Sigma E_{\mathrm{dh}}$, confirming the geometric, magnetic and energetic criteria of aromaticity. The electronic features of the LPA mimics assessed by analysing molecular electrostatic potential topography and molecular orbitals have shown that the LPA cores retain the reactivity of the parent LPA. Furthermore, significant mixing of the $\mathrm{N}$-lone pairs of the heterocycle with carbon $\pi$-orbitals improves aromaticity and decreases the HOMO-LUMO energy gap.
\end{abstract}

\section{Introduction}

Linear polyacenes (LPAs), aromatic hydrocarbons composed of linearly fused benzene rings ${ }^{1}{ }^{1}$ possess attractive optical and electronic properties suitable for nanotechnology applications, organic electronics, ${ }^{2}$ lithium ion batteries, ${ }^{3}$ ferromagnetic materials, ${ }^{4}$ etc. The optoelectronic application potential of these molecules is linked to their ability to tune the HOMOLUMO gap with the increase in the oligomer size, ${ }^{5,6}$ strong solid state two dimensional interactions in the electronic level, ${ }^{5}$ and charge mobility. ${ }^{5,7,8}$ Among the LPAs, pentacene is widely studied due to its optical and semiconducting properties suitable for applications in the area of organic field effect transistors. Though LPA systems longer than pentacene such as heptacene,

Chemical Sciences and Technology Division, Academy of Scientific and Innovative Research (AcSIR), CSIR-National Institute for Interdisciplinary Science and Technology (CSIR-NIIST), Thiruvananthapuram 695019, India.

E-mail: sureshch@gmail.com, sureshch@niist.res.in

$\dagger$ Electronic supplementary information (ESI) available: Optimised geometries, correlation plots, HOMO-LUMO and MESP figures, SCF energy and NICS values etc. See DOI: $10.1039 / \mathrm{c} 6 \mathrm{cp} 03723 \mathrm{~b}$ octacene and nonacene have been synthesized on a polymer matrix by photogeneration, the application potential of their p-type semiconducting properties is very limited due to chemical instability. ${ }^{9-11}$ According to Clar's theory, a LPA system is inherently more reactive with the increase in its length due to the phenomenon of aromatic dilution. ${ }^{12,13}$

Clar's rule of aromatic sextets is a very powerful tool to describe the properties of $\mathrm{sp}^{2}$-carbon bonded systems like polycyclic aromatic hydrocarbons (PAH) ${ }^{14}$ Clar proposed that in the case of $\mathrm{PAH}$, the one showing the greatest number of localized sextets and the minimum number of localized double bonds is the most aromatic and most stable. ${ }^{15,16}$ For instance, in the isomeric 4-ring systems given in Scheme 1, the aromaticity follows

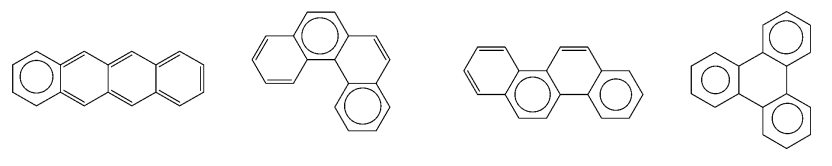

Scheme 1 Clar's sextet formula for isomeric 4-ring systems, from left tetracene, benzophenanthrene, chrysene, and triphenylene. 


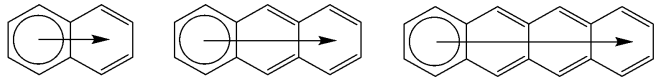

Scheme 2 Clar's notation to show the aromatic dilution in linear polyacenes.

the order tetracene $<$ benzophenanthrene $\approx$ chrysene $<$ triphenylene. In the LPA topology of tetracene, one can draw only one sextet of $\pi$-electrons in Clar's formula (Scheme 1) whereas more than one sextet is possible for all other topologies. ${ }^{17}$ With the increase in the length of LPAs, the aromatic character decreases as only one sextet can be delocalized for the whole system, which leads to significant double bond localization in the molecule and higher reactivity (Scheme 2). The arrow emanating from the sextet ring in Scheme 2 suggests aromatic dilution. Bultinck et al. derived the atoms-in-molecule based six centre index (SCI-AIM) to study the electron delocalization in a linear polyacene series and showed that aromaticity decreases on going from outer to inner rings. ${ }^{18}$ Aromaticity is currently described as a multidimensional phenomenon, related to the structural, electronic, magnetic and energetic properties of molecules. ${ }^{19-26}$ A large volume of literature exists in the case of linear polyacenes dedicated to the understanding of magnetic properties and aromaticity. ${ }^{27-30}$

Since LPAs larger than pentacene are chemically highly unstable, one practical way to introduce more fused hexagonal rings in the chain is by designing suitable LPA mimics. This could be done by doping heteroatoms into the LPA framework. ${ }^{2,31}$ The nitrogen atom, isoelectronic with $\mathrm{C}-\mathrm{H}$, is an immediate choice to integrate into the acene skeleton as this could retain the $\pi$-conjugation features of the molecule. ${ }^{32}$ Synthetic strategies utilizing condensation reactions, ${ }^{33,34}$ coupling reactions, ${ }^{35-38}$ Diel's Alder reactions, ${ }^{39}$ and oxidative coupling reactions have been utilized for the synthesis of N-heteroacenes. ${ }^{40-46}$ Large N-heteroacenes have been known since the beginning of the 20 th century ${ }^{47,48}$ and are still being intensively researched. ${ }^{32,49-56}$ Many diazapentacene derivatives have been successfully utilized as electronic materials in thin film transistors. ${ }^{51,57-62}$

Herein we propose that by fusing LPA moieties with two N-H units, large LPA mimics can be designed which could show substantial improvement in the aromatic character of the LPA core. The incorporation of the $\mathrm{N}-\mathrm{H}$ units proposes the utilization of $\mathrm{N}$-lone pairs to enhance the $\pi$-electron conjugation as well as the net electron content within a hexagon in the molecule. This design strategy improves the aromatic sextet distribution in the LPA mimics and suggests the formation of stable oligomeric and even polymeric long chain mimics of LPAs. In such systems, the $\mathrm{N}$-heterocyclic connection between two LPA moieties is fulfilled by a 1,4-dihydropyrazine unit. Even though the existence of 1,4dihydropyrazine derivatives was known, the successful synthesis of a carboxylic acid ester derivative was performed in the year 1969 only. ${ }^{63}$ The structure of these alleged 1,4-dihydropyrazines came into the scene a year after that. ${ }^{64}$ The photophysical properties of $\mathrm{N}, \mathrm{N}$-dimethyl derivatives of the above mentioned pyrazines were also widely studied. ${ }^{65}$ The successful synthesis of the non-substituted system took one more year for completion. ${ }^{66}$
Attempts for an easy and economical synthesis of such systems are continuing. ${ }^{67-70}$ Linear extensions of dihydropyrazine moieties connected through benzene groups are known and among them three benzene groups interconnected by two dihydropyrazine groups are termed tetraazapentacenes. ${ }^{71,72}$ Halogen substituted tetraazapentacenes have been successfully synthesized, ${ }^{72}$ but not the unsubstituted ones. 6,13-Dihydrodibenzo[ $b, i]$ phenazine is successfully synthesised which can be used as a pentacene substitute having superior qualities. ${ }^{57}$

\section{Computational method}

All the molecules have been optimized using the M06L/6$311++G(d, p)$ level of density functional theory (DFT) as implemented in the Gaussian09 suite of programs. ${ }^{73-75}$ All the optimized structures are confirmed as energy minima by vibrational frequency calculation. The wavefunction generated using M06L/6-311++G(d,p) is used for molecular electrostatic potential (MESP) calculations. For all the molecules, the aromaticity of each ring is quantified by computing the nucleus independent chemical shift (NICS) ${ }^{76}$ at the ring center $(\operatorname{NICS}(0))$. Also NICS at $1 \AA$ above the ring center (NICS(1)) and the $z$-component of NICS at $1 \AA$ above the ring center $\left(\operatorname{NICS}(1)_{z z}\right)$ are calculated. The harmonic oscillator model of the aromaticity (HOMA) index is calculated for all the systems using the procedure of Krygowski et al. ${ }^{77}$ The selection of the M06L functional (meta-GGA local functional with $0 \%$ Hartree-Fock (HF) exchange) is based on a previous benchmark study which showed that this method can yield a reliable geometry and interaction energy close to the $\operatorname{CCSD}(\mathrm{T})$ level accuracy for a variety of non-covalent dimers. ${ }^{78}$ Furthermore, recent studies conducted using this method on a variety of systems have provided reliable results in agreement with high accuracy ab initio methods and dispersion-corrected DFT methods. ${ }^{79-81}$ In order to further substantiate the use of this method to study the present set of molecules, we have done calculations using two more Minnesota functionals, viz. M06/6-311++G(d,p) (hybrid meta-GGA method with $27 \%$ HF exchange) and M06-2X/6-311++G(d,p) (hybrid meta-GGA method with $54 \%$ HF exchange) for a representative series of molecules.

\section{Results and discussion}

\section{Design strategy}

The molecular design strategy is based on improving Clar's sextet distribution in the LPA mimics. Benzene has the perfect aromatic sextet and its six $\pi$-electrons are delocalized over six CC bonds meaning that the number of $\pi$-electrons per CC bond $\left(n_{\pi}\right)$ is 1 . In all PAH systems, $n_{\pi}$ is always less than 1 and for LPA series, this value decreases with the increase in the length. For instance, for naphthalene, anthracene, tetracene, and pentacene, $n_{\pi}$ is $0.91,0.88,0.86$ and 0.85 , respectively. By fusing two LPA moieties through two - NH- units, a higher LPA mimic can be designed. Every fusion point will represent a 1,4-dihydropyrazine unit. In the LPA mimic, the formal $\pi$-electron count of every $\mathrm{N}$-heterocycle is 8 , which does not follow Hückel's rule, and hence, 

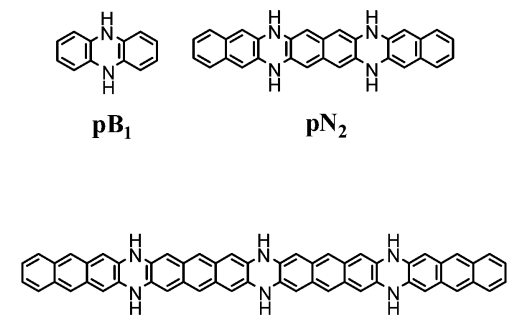

$\mathbf{p A}_{3}$

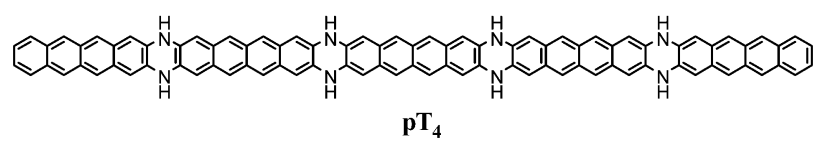

Fig. 1 Representative structures of the molecules under study containing 1,4-dihydropyrazine-type $\mathrm{N}$-heterocycles.

is antiaromatic. However, as the $n_{\pi}$ electron count of the LPA decreases, electron flow from the electron rich N-heterocycle to the hydrocarbon core is expected which could stabilize the system. We use a notation that uses two letters and one number to represent each of the designed systems. The first letter in the notation is $\mathrm{p}$ which represents the 1,4-dihydropyrazine-type character of the $\mathrm{N}$-heterocycle while the second letter $\mathrm{B}, \mathrm{N}, \mathrm{A}$ or $\mathrm{T}$ represents the core unit made up of benzene, naphthalene, anthracene or tetracene moieties, respectively. Furthermore, the numbers $1,2,3,4,5$ and 6 represent the number of 1,4-dihydropyrazine-type $\mathrm{N}$-heterocycles in the molecule. For a system having ' $n$ ' dihydropyrazine moieties, there will be ' $n+1$ ' benzene, naphthalene, anthracene or tetracene units present. For example, $\mathrm{pB}_{1}$ made up of one 1,4-dihydropyrazine-type heterocycle and two benzene cores is the dihydrophenazine molecule (Fig. 1). Similarly $\mathrm{pN}_{2}$ represents an LPA mimic made up of three naphthalene cores and two 1,4-dihydropyrazine-type $\mathrm{N}$-heterocycles. The dihydropyrazine systems selected for this study are $\mathrm{pB}_{1}-\mathrm{pB}_{6}, \mathrm{pN}_{1}-\mathrm{pN}_{6}, \mathrm{pA}_{1}-\mathrm{pA}_{6}$ and $\mathrm{pT}_{1}-\mathrm{pT}_{6}$ (ESI $\dagger$ ).

In Table 1 , the $n_{\pi}$ value of all the LPA mimics is depicted along with the $n_{\pi}$ value of the LPA. It is very clear that annulation of an LPA with $\mathrm{N}$-heterocycles improves the net electron content of the LPA mimic. This effect is dominant in the $\mathrm{pB}$ series as all molecules retain an $n_{\pi}$ value of 1 for all benzene cores. In the $\mathrm{pN}, \mathrm{pA}$ and $\mathrm{pT}$ series, $n_{\pi}$ is always higher than the LPA core and it increases with the increase in the length of the molecule. Hence, an increase in aromatic character is expected with the increase in the net electron content of the system.

Table 1 The ratio of the number of $\pi$ electrons to the total number of bonds $\left(n_{\pi}\right)$ in LPAs and LPA-based heterocycles. B, N, A and T represent benzene, naphthalene, anthracene and tetracene, respectively

\begin{tabular}{llllllll}
\hline System & $n_{\pi}$ & System & $n_{\pi}$ & System & $n_{\pi}$ & System & $n_{\pi}$ \\
\hline $\mathrm{B}$ & 1.000 & $\mathrm{~N}$ & 0.909 & $\mathrm{~A}$ & 0.875 & $\mathrm{~T}$ & 0.857 \\
$\mathrm{pB}_{1}$ & 1.000 & $\mathrm{pN}_{1}$ & 0.923 & $\mathrm{pA}_{1}$ & 0.889 & $\mathrm{pT}_{1}$ & 0.870 \\
$\mathrm{pB}_{2}$ & 1.000 & $\mathrm{pN}_{2}$ & 0.927 & $\mathrm{pA}_{2}$ & 0.893 & $\mathrm{pT}_{2}$ & 0.873 \\
$\mathrm{pB}_{3}$ & 1.000 & $\mathrm{pN}_{3}$ & 0.929 & $\mathrm{pA}_{3}$ & 0.895 & $\mathrm{pT}_{3}$ & 0.875 \\
$\mathrm{pB}_{4}$ & 1.000 & $\mathrm{pN}_{4}$ & 0.930 & $\mathrm{pA}_{4}$ & 0.896 & $\mathrm{pT}_{4}$ & 0.876 \\
$\mathrm{pB}_{5}$ & 1.000 & $\mathrm{pN}_{5}$ & 0.930 & $\mathrm{pA}_{5}$ & 0.897 & $\mathrm{pT}_{5}$ & 0.877 \\
$\mathrm{pB}_{6}$ & 1.000 & $\mathrm{pN}_{6}$ & 0.931 & $\mathrm{pA}_{6}$ & 0.897 & $\mathrm{pT}_{6}$ & 0.877
\end{tabular}

\[ \mathbf{p N}_{\mathbf{3}} \]
Fig. 2 Representative set of molecules to distinguish zigzag pB and planar all other series.

The molecules in the $\mathrm{pB}$ series show a zigzag structure with respect to the orientation of the six-membered rings as shown in Fig. 2 while all other systems exhibit a planar structure. In the pB series, pyramidalisation to the NH group occurs in every ring and leads to the zigzag structure. This phenomenon can be attributed to the fact that benzene cores in the $\mathrm{pB}$ series possess a full sextet of electrons and thus are reluctant to accept lone pair electron density from N. Thus, N-centers adopt a pyramidal configuration to avoid destabilization from inherent Hückel antiaromaticity within the N-heterocycle.

\section{Dehydrogenation energy}

In a recent review on the topic of large heterocyclic acenes, Bunz described that hydrogenation of $\mathbf{1}$ to 2 is exothermic by $49.5 \mathrm{kcal} \mathrm{mol}^{-1}$ and thermodynamically favourable while hydrogenation of 2 to 3 is endothermic by $2.5 \mathrm{kcal} \mathrm{mol}^{-1}$ (Fig. 3). ${ }^{82}$ In the present study, 3 is $\mathrm{pB}_{2}$. Bunz also correlated the synthesis of terminal substituted 2 with its thermodynamic stability. However our theoretical calculations using the method used by Bunz (B3LYP/6-31G**) suggest that hydrogenation of 1 to 2 and 2 to 3 is exothermic by 42.5 and $16.3 \mathrm{kcal} \mathrm{mol}^{-1}$, respectively. It indicates an error in the previous calculation. Furthermore, at the M06L/ $6-311++G(d, p)$ level too, both hydrogenation reactions are found to be exothermic and the hydrogenation energy values are in agreement with the B3LYP method (hydrogenation of 1 to 2 and 2 to 3 are exothermic by -40.02 and $-10.38 \mathrm{kcal}^{\mathrm{mol}}{ }^{-1}$, respectively). In order to assess the thermodynamic stability of the systems $\left(\mathrm{pB}_{1}-\mathrm{pB}_{6}, \mathrm{pN}_{1}-\mathrm{pN}_{6}, \mathrm{pA}_{1}-\mathrm{pA}_{6}\right.$ and $\left.\mathrm{pT}_{1}-\mathrm{pT}_{6}\right)$, the energy change associated with dehydrogenation of $\mathrm{N}$-centers is calculated.

The dehydrogenation energy $\left(E_{\mathrm{dh}}\right)$ corresponding to the $\mathrm{N}$-heterocycles of all the set of molecules is given in Table 2 at the M06L/6-311++G(d,p) level. The notation N1, N2, etc. is used to indicate the number of $\mathrm{N}$-heterocycles dehydrogenated in the molecule, starting from one terminal to the other.

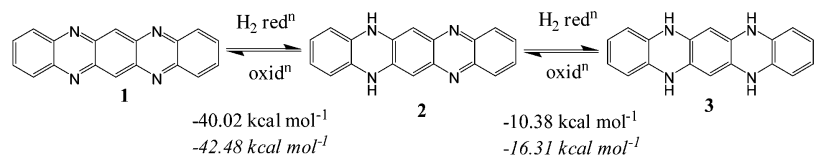

Fig. 3 Calculated heats of hydrogenation for the reduction of 1 to 2 and 2 to 3 . Values in regular font are for the M06L/6-311++G(d,p) level and those in italics are for the B3LYP/6-31G** level. 
Table 2 Dehydrogenation energy $E_{\mathrm{dh}}\left(\mathrm{kcal} \mathrm{mol}^{-1}\right)$ of the $\mathrm{N}$-heterocycles of LPA mimics

\begin{tabular}{lllllllr}
\hline & $\mathrm{N} 1$ & $\mathrm{~N} 2$ & $\mathrm{~N} 3$ & $\mathrm{~N} 4$ & $\mathrm{~N} 5$ & $\mathrm{~N} 6$ & $\Sigma E_{\mathrm{dh}}$ \\
\hline $\mathrm{pB}_{1}$ & 23.8 & & & & & & 23.8 \\
$\mathrm{pB}_{2}$ & 40.0 & 12.2 & & & & & 52.2 \\
$\mathrm{pB}_{3}$ & 45.6 & 25.8 & 11.3 & & & & 82.7 \\
$\mathrm{pB}_{4}$ & 47.9 & 30.4 & 24.0 & 11.2 & & & 113.5 \\
$\mathrm{pB}_{5}$ & 48.8 & 32.7 & 27.2 & 24.6 & 11.1 & & 144.4 \\
$\mathrm{pB}_{6}$ & 49.5 & 34.1 & 30.2 & 27.4 & 18.7 & 15.6 & 175.5 \\
$\mathrm{pN}_{1}$ & 38.8 & & & & & & 38.8 \\
$\mathrm{pN}_{2}$ & 48.0 & 32.9 & & & & & 80.9 \\
$\mathrm{pN}_{3}$ & 47.4 & 41.8 & 31.9 & & & & 121.1 \\
$\mathrm{pN}_{4}$ & 39.3 & 44.0 & 40.3 & 31.6 & & & 155.2 \\
$\mathrm{pN}_{5}$ & 34.3 & 44.6 & 24.7 & 57.6 & 31.7 & & 192.9 \\
$\mathrm{pN}_{6}$ & 31.3 & 45.0 & 43.3 & 41.8 & 39.6 & 31.4 & 232.4 \\
$\mathrm{pA}_{1}$ & 46.3 & & & & & & 46.3 \\
$\mathrm{pA}_{2}$ & 51.6 & 43.1 & & & & & 94.7 \\
$\mathrm{pA}_{3}$ & 38.7 & 48.2 & 42.6 & & & & 129.5 \\
$\mathrm{pA}_{4}$ & 32.9 & 49.2 & 47.6 & 42.7 & & & 172.4 \\
$\mathrm{pA}_{5}$ & 49.1 & 43.3 & 35.7 & 47.4 & 42.3 & & 217.8 \\
$\mathrm{pA}_{6}$ & 18.5 & 49.6 & 48.8 & 49.7 & 45.9 & 42.3 & 254.8 \\
$\mathrm{pT}_{1}$ & 50.3 & & & & & & 50.3 \\
$\mathrm{pT}_{2}$ & 41.0 & 48.2 & & & & & 89.2 \\
$\mathrm{pT}_{3}$ & 45.51 & 39.8 & 47.9 & & & & 153 \\
$\mathrm{pT}_{4}$ & 44.2 & 32.5 & 51.0 & 47.9 & & & 175.6 \\
$\mathrm{pT}_{5}$ & 15.9 & 51.8 & 51.4 & 50.9 & 47.7 & & 217.7 \\
$\mathrm{pT}_{6}$ & 33.6 & 49.6 & 47.5 & 32.0 & 50.9 & 47.7 & 261.3 \\
\hline & & & & & & & \\
\hline
\end{tabular}

All the reactions are endothermic suggesting that the hydrogenrich states are more stable than the dehydrogenated states. This is very clear from the total $E_{\mathrm{dh}}$ given in Table 2 . The increase in the total $E_{\mathrm{dh}}\left(\Sigma E_{\mathrm{dh}}\right)$ is proportional to the increase in the number of heterocycles and the increase in the size of the PAH moiety. In $\mathrm{pB}_{1}, \mathrm{pN}_{1}, \mathrm{pA}_{1}$ and $\mathrm{pT}_{1}$ systems, $E_{\mathrm{dh}}$ values are $23.8,38.8,46.3$, and $50.3 \mathrm{kcal} \mathrm{mol}^{-1}$, respectively. These numbers show a strong linear correlation with the $n_{\pi}$ values of benzene, naphthalene, anthracene and tetracene (ESI $\dagger$ ). This correlation suggests that lone pair donation from nitrogen to the $\pi$-system increases with a decrease in the $n_{\pi}$ value and that enhances the overall $\pi$-bonding strength and aromaticity of the system. As a result, the dehydrogenation reaction becomes increasingly more difficult for larger acene mimics. For instance, $E_{\mathrm{dh}}$ corresponding to the dehydrogenation of all the $\mathrm{N}$-heterocycles, viz. two in $\mathrm{pB}_{2}, \mathrm{pN}_{2}, \mathrm{pA}_{2}$ and $\mathrm{pT}_{2}$, three in $\mathrm{pB}_{3}$, $\mathrm{pN}_{3}, \mathrm{pA}_{3}$ and $\mathrm{pT}_{3}$, four in $\mathrm{pB}_{4}, \mathrm{pN}_{4}, \mathrm{pA}_{4}$ and $\mathrm{pT}_{4}$, five in $\mathrm{pB}_{5}$, $\mathrm{pN}_{5}, \mathrm{pA}_{5}$ and $\mathrm{pT}_{5}$ and six in $\mathrm{pB}_{6}, \mathrm{pN}_{6}, \mathrm{pA}_{6}$ and $\mathrm{pT}_{6}$ gradually increases, proportional to the decrease in $n_{\pi}$ of the system (in all cases, $n_{\pi}$ versus $E_{\mathrm{dh}}$ correlations show a correlation coefficient in the range 0.997-0.999).

\section{Bond length equalization and aromatic character}

Geometry-based indices have been used for quantifying aromaticity especially in the case of planar systems. ${ }^{77,83}$ The bond length based index of aromaticity, HOMA developed by Krygowski et al. is one of the most prominent indices among this category and is used to compare the aromaticity of a variety of organic molecules. ${ }^{77}$ For a perfect aromatic system, HOMA is 1 and a value close to zero indicates non-aromatic character.

Aromatic molecules tend to show bond length equalization and a HOMA value close to 1 . The CC bond length of benzene
Table 3 HOMA index of symmetrically distinguishable rings in the $p B$ series of LPA mimics

\begin{tabular}{lllllll}
\hline & $\mathrm{pB}_{1}$ & $\mathrm{pB}_{2}$ & $\mathrm{pB}_{3}$ & $\mathrm{pB}_{4}$ & $\mathrm{pB}_{5}$ & $\mathrm{pB}_{6}$ \\
\hline Cring1 & 0.98 & 0.98 & 0.98 & 0.98 & 0.98 & 0.98 \\
Nring1 & 0.69 & 0.68 & 0.68 & 0.67 & 0.67 & 0.67 \\
Cring2 & & 0.99 & 0.99 & 0.99 & 0.99 & 0.99 \\
Nring2 & & & 0.66 & 0.67 & 0.66 & 0.65 \\
Cring3 & & & & 0.99 & 0.99 & 0.99 \\
Nring3 & & & & & 0.66 & 0.66 \\
Cring4 & & & & & & 0.99 \\
¿HOMA & \multirow{2}{*}{1.67} & 2.65 & 3.31 & 4.3 & 4.95 & 5.93 \\
\hline
\end{tabular}

(1.391 $\AA$ at M06L/6-311++G(d,p) level) is considered to be the most optimum for an aromatic hydrocarbon. In the present study, the notation Nring1, Nring2, etc. is used to indicate the most peripheral rings to the interior symmetrically distinguishable N-heterocycles. Similarly, the notation Cring1, Cring2, etc. is used to indicate the most peripheral rings to the interior carbon rings. The HOMA indices calculated for all the molecules are depicted in Tables 3-6. In the pB series, the HOMA of every benzene unit is 0.98 or 0.99 , showing the perfect aromatic nature of the individual benzene rings. Furthermore, the $\mathrm{N}$-heterocycle has a HOMA in the range $0.65-0.69$ which indicates substantial aromatic character as only a $30-35 \%$ reduction in aromaticity is observed compared to the HOMA of 1.00 for one of the most aromatic $\mathrm{N}$-heterocycles, pyridine. In the $\mathrm{pN}$ series, among the carbon rings, the terminal ring is the most aromatic with its HOMA being $0.85-0.86$ whereas the ring adjacent to it is the least aromatic (HOMA 0.76-0.77). In $\mathrm{pN}_{3}-\mathrm{PN}_{5}$, both rings of the interior naphthalene units show nearly the same aromatic character (HOMA $0.80-0.82$ ) and the N-heterocycles show slightly higher values $(0.68-0.71)$ than the $\mathrm{pB}$ series. In the case of $\mathrm{pA}_{1}$, the HOMA of Cring1, Cring2, and Cring3 is 0.72, 0.74 and 0.65, respectively. This pattern and magnitude of HOMA is retained in $\mathrm{pA}_{2}-\mathrm{pA}_{5}$. Furthermore, HOMA $0.68-0.75$ is observed for the carbon rings of all other anthracene moieties whereas a slightly lower HOMA $0.65-0.68$ is observed for all dihydropyrazine rings. In the case of the pT series, all the terminal tetracene moieties show nearly identical HOMA patterns with terminal, second, third and fourth carbon rings showing values of $0.64-0.65,0.67-0.68$, $0.64-0.65$, and 0.58 , respectively. The inner tetracene moieties show HOMA values in the range $0.61-0.67$ whereas the aromatic character of N-heterocycles is in the range $0.62-0.64$, the lowest

Table 4 HOMA index of symmetrically distinguishable rings in the $\mathrm{pN}$ series of LPA mimics

\begin{tabular}{lllllll}
\hline & $\mathrm{pN}_{1}$ & $\mathrm{pN}_{2}$ & $\mathrm{pN}_{3}$ & $\mathrm{pN}_{4}$ & $\mathrm{pN}_{5}$ & $\mathrm{pN}_{6}$ \\
\hline Cring1 & 0.85 & 0.85 & 0.85 & 0.85 & 0.86 & 0.86 \\
Cring2 & 0.77 & 0.76 & 0.76 & 0.77 & 0.77 & 0.77 \\
Nring1 & 0.69 & 0.69 & 0.69 & 0.70 & 0.70 & 0.70 \\
Cring3 & & 0.80 & 0.81 & 0.82 & 0.82 & 0.82 \\
Cring4 & & & 0.80 & 0.81 & 0.81 & 0.81 \\
Nring2 & & & 0.70 & 0.68 & 0.71 & 0.71 \\
Cring5 & & & & 0.81 & 0.82 & 0.82 \\
Cring6 & & & & & 0.81 & 0.81 \\
Nring3 & & & & & 0.71 & 0.71 \\
Cring7 & & & & & & 0.81 \\
¿HOMA & 2.31 & 3.1 & 4.61 & 5.44 & 7.01 & 7.82
\end{tabular}


Table 5 HOMA index of symmetrically distinguishable rings in the $\mathrm{pA}$ series of LPA mimics

\begin{tabular}{|c|c|c|c|c|c|c|}
\hline & $\mathrm{pA}_{1}$ & $\mathrm{pA}_{2}$ & $\mathrm{pA}_{3}$ & $\mathrm{pA}_{4}$ & $\mathrm{pA}_{5}$ & $\mathrm{pA}_{6}$ \\
\hline Cring1 & 0.72 & 0.73 & 0.72 & 0.72 & 0.72 & 0.72 \\
\hline Cring2 & 0.74 & 0.74 & 0.74 & 0.74 & 0.74 & 0.74 \\
\hline Cring3 & 0.65 & 0.65 & 0.65 & 0.65 & 0.65 & 0.65 \\
\hline Nring1 & 0.65 & 0.65 & 0.65 & 0.65 & 0.65 & 0.65 \\
\hline Cring4 & & 0.69 & 0.69 & 0.69 & 0.69 & 0.69 \\
\hline Cring5 & & 0.75 & 0.75 & 0.75 & 0.75 & 0.75 \\
\hline Cring6 & & & 0.68 & 0.68 & 0.68 & 0.68 \\
\hline Nring2 & & & 0.66 & 0.66 & 0.66 & 0.66 \\
\hline Cring7 & & & & 0.69 & 0.69 & 0.69 \\
\hline Cring8 & & & & 0.75 & 0.75 & 0.75 \\
\hline Cring9 & & & & & 0.68 & 0.68 \\
\hline Nring3 & & & & & 0.66 & 0.66 \\
\hline Cring10 & & & & & & 0.68 \\
\hline Cring11 & & & & & & 0.75 \\
\hline$\Sigma$ HOMA & 2.76 & 4.21 & 5.54 & 6.98 & 8.32 & 9.75 \\
\hline
\end{tabular}

Table 6 HOMA index of symmetrically distinguishable rings in the pT series of LPA mimics

\begin{tabular}{llllllr}
\hline & $\mathrm{pT}_{1}$ & $\mathrm{pT}_{2}$ & $\mathrm{pT}_{3}$ & $\mathrm{pT}_{4}$ & $\mathrm{pT}_{5}$ & $\mathrm{pT}_{6}$ \\
\hline Cring1 & 0.64 & 0.64 & 0.65 & 0.65 & 0.65 & 0.65 \\
Cring2 & 0.68 & 0.68 & 0.67 & 0.67 & 0.67 & 0.68 \\
Cring3 & 0.65 & 0.65 & 0.65 & 0.65 & 0.64 & 0.65 \\
Cring4 & 0.58 & 0.58 & 0.58 & 0.58 & 0.58 & 0.58 \\
Nring1 & 0.62 & 0.62 & 0.64 & 0.62 & 0.63 & 0.64 \\
Cring5 & & 0.61 & 0.61 & 0.61 & 0.61 & 0.61 \\
Cring6 & & 0.67 & 0.67 & 0.67 & 0.67 & 0.67 \\
Cring7 & & & 0.66 & 0.67 & 0.67 & 0.67 \\
Cring8 & & & 0.61 & 0.61 & 0.61 & 0.61 \\
Nring2 & & & 0.63 & 0.63 & 0.63 & 0.63 \\
Cring9 & & & & 0.61 & 0.61 & 0.61 \\
Cring10 & & & & 0.67 & 0.67 & 0.67 \\
Cring11 & & & & & 0.67 & 0.67 \\
Cring12 & & & & & 0.61 & 0.61 \\
Nring3 & & & & & 0.63 & 0.63 \\
Cring13 & & & & & & 0.61 \\
Cring14 & & & & & & 0.67 \\
¿HOMA & 3.17 & 4.45 & 6.37 & 7.64 & 9.55 & 10.86 \\
& & & & & &
\end{tabular}

compared to all other systems. The HOMA of benzene (1.00), naphthalene (0.77), anthracene (0.62 for Cring1, 0.70 for Cring2), and tetracene ( 0.53 for Cring1, 0.60 for Cring2) is almost fully retained or even enhanced in all the respective carbon rings in the LPA-based N-heterocyclic systems. The sum of the HOMA values of all the rings can be considered as a measure of the global aromaticity of the molecules. This quantity referred to as $\Sigma$ HOMA is also depicted in Tables 3-6. The इHOMA of all the different series of compounds show strong linear correlations with the corresponding total dehydrogenation energy $\Sigma E_{\mathrm{dh}}$ (Fig. 4). These correlations strongly suggest that $E_{\mathrm{dh}}$ values are intimately connected with the aromatization energy of the molecule. According to Clar, the LPA systems show 'aromatic dilution' with the increase in the length of the molecule. This phenomenon is clearly visible in the correlation plots shown in Fig. 4 in terms of the decrease in slope as we move from $\mathrm{pB}$ to $\mathrm{pN}$ to $\mathrm{pA}$ to $\mathrm{pT}$ series of molecules.

\section{Nucleus independent chemical shift and aromatic character}

Magnetic criteria for aromaticity are popularly described in terms of the NICS index as portrayed by Schleyer and co-workers. ${ }^{76}$

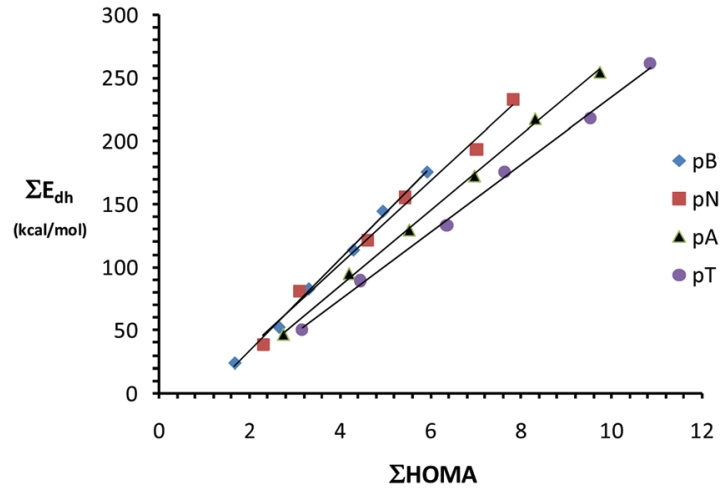

Fig. 4 Correlation between the HOMA index and dehydrogenation energy.

We have analyzed three NICS indices, viz. the NICS at the center of each six-membered ring (NICS $(0))$, at $1 \AA$ above every ring center (NICS(1)) and also the $z$-component of the NICS at $1 \AA$ above the ring center $\left(\operatorname{NICS}_{z z}(1)\right)$. Among these indices, $\operatorname{NICS}_{z z}(1)$ is considered to be more reliable than others and for all the discussions, this quantity is used in the text and others are provided in the ESI. $\dagger$ In fact, the relative ordering of the magnitude of all three indices is very similar and so the conclusions drawn from any of them are the same.

The $\operatorname{NICS}_{z z}(1)$ values of benzene, naphthalene, Cring1 of anthracene and Cring1 of tetracene are $-17.30,-28.65,-26.32$ and -23.95 , respectively and those of Cring 2 of anthracene and Cring2 of tetracene are -34.11 and -33.85 , respectively. These values may give a false impression that benzene is the least aromatic and the most aromatic is Cring2 of anthracene or tetracene. The discrepancies in the NICS, its size-, shape- and distance dependencies as well as more sophisticated approaches to the NICS treatment of aromaticity have been elaborated in the past. ${ }^{84}$ We do not attempt to directly compare the NICS of PAH molecules and LPA mimics because this index varies with respect to the number of heteroatoms, size and symmetry of the molecules. Since the NICS works best for comparing the aromaticity of a similar set of molecules, we will focus on the relative ordering of the NICS along the symmetrically distinguishable rings, starting from one at the terminal to the last in the middle.

In all the $\mathrm{pB}, \mathrm{pN}, \mathrm{pA}$, and $\mathrm{pT}$ series of molecules, the Crings show significantly negative $\mathrm{NICS}_{z z}(1)$ indicating aromatic character whereas all the Nrings show positive $\operatorname{NICS}_{z z}(1)$ indicating antiaromaticity (Tables 7-10). In the pB series, the negative character

Table $7 \quad \mathrm{NICS}_{z z}(1)$ values of symmetrically distinguishable rings in the $\mathrm{pB}$ series of LPA mimics

\begin{tabular}{lrrrrrr}
\hline & $\mathrm{pB}_{1}$ & \multicolumn{1}{c}{$\mathrm{pB}_{2}$} & \multicolumn{1}{c}{$\mathrm{pB}_{3}$} & \multicolumn{1}{c}{$\mathrm{pB}_{4}$} & \multicolumn{1}{c}{$\mathrm{pB}_{5}$} & \multicolumn{1}{c}{$\mathrm{pB}_{6}$} \\
\hline Cring1 & -15.56 & -17.94 & -18.03 & -18.69 & -19.22 & -19.98 \\
Nring1 & 18.49 & 16.10 & 16.26 & 16.51 & 16.51 & 16.69 \\
Cring2 & & -7.02 & -7.32 & -7.08 & -6.70 & -6.45 \\
Nring2 & & & 13.65 & 13.83 & 14.00 & 14.02 \\
Cring3 & & & & -8.68 & -8.63 & -8.83 \\
Nring3 & & & & & 13.60 & 13.66 \\
Cring4 & & & & & & -8.71
\end{tabular}


Table $8 \quad \mathrm{NICS}_{z z}(1)$ values of symmetrically distinguishable rings in the $\mathrm{pN}$ series of LPA mimics

\begin{tabular}{lrrrrrr}
\hline & \multicolumn{1}{c}{$\mathrm{pN}_{1}$} & \multicolumn{1}{c}{$\mathrm{pN}_{2}$} & \multicolumn{1}{c}{$\mathrm{pN}_{3}$} & \multicolumn{1}{c}{$\mathrm{pN}_{4}$} & \multicolumn{1}{c}{$\mathrm{pN}_{5}$} & \multicolumn{1}{c}{$\mathrm{pN}_{6}$} \\
\hline Cring1 & -22.65 & -22.39 & -22.46 & -22.17 & -22.12 & -21.86 \\
Cring2 & -14.48 & -14.53 & -14.10 & -14.11 & -14.19 & -14.18 \\
Nring1 & 19.18 & 19.14 & 19.24 & 19.20 & 19.30 & 19.34 \\
Cring3 & & -9.95 & -9.80 & -9.64 & -9.35 & -9.13 \\
Cring4 & & & -10.40 & -10.57 & -10.57 & -10.82 \\
Nring2 & & & 18.27 & 18.21 & 18.47 & 18.51 \\
Cring5 & & & & -10.35 & -10.06 & -9.86 \\
Cring6 & & & & & -10.30 & -10.45 \\
Nring3 & & & & & 18.70 & 18.70 \\
Cring7 & & & & & & -10.10 \\
\end{tabular}

Table $9 \mathrm{NICS}_{z z}(1)$ values of symmetrically distinguishable rings in the $\mathrm{pA}$ series

\begin{tabular}{lllrrrr}
\hline & $\mathrm{pA}_{1}$ & \multicolumn{1}{c}{$\mathrm{pA}_{2}$} & \multicolumn{1}{c}{$\mathrm{pA}_{3}$} & \multicolumn{1}{c}{$\mathrm{pA}_{4}$} & \multicolumn{1}{c}{$\mathrm{pA}_{5}$} & \multicolumn{1}{c}{$\mathrm{pA}_{6}$} \\
\hline Cring1 & -23.70 & -23.09 & -22.94 & -22.78 & -22.49 & -22.47 \\
Cring2 & -26.77 & -26.36 & -25.93 & -25.68 & -25.49 & -25.38 \\
Cring3 & -14.68 & -14.82 & -15.32 & -15.68 & -16.02 & -16.41 \\
Nring1 & 14.84 & 15.11 & 15.19 & 15.25 & 15.29 & 15.13 \\
Cring4 & & -12.51 & -11.79 & -11.45 & -11.02 & -10.64 \\
Cring5 & & -21.31 & -21.25 & -21.21 & -21.15 & -21.26 \\
Cring6 & & & -12.82 & -13.04 & -13.32 & -13.74 \\
Nring2 & & & 15.52 & 15.56 & 15.64 & 15.69 \\
Cring7 & & & & -12.36 & -11.93 & -11.60 \\
Cring8 & & & & -21.11 & -20.97 & -21.01 \\
Cring9 & & & & & -12.56 & -13.00 \\
Nring3 & & & & & 15.63 & 15.60 \\
Cring10 & & & & & & -12.21 \\
Cring11 & & & & & &
\end{tabular}

Table $10 \quad \mathrm{NICS}_{z z}(1)$ values of symmetrically distinguishable rings in the $\mathrm{pT}$ series of LPA mimics

\begin{tabular}{llllllr}
\hline & $\mathrm{pT}_{1}$ & $\mathrm{pT}_{2}$ & \multicolumn{1}{c}{$\mathrm{pT}_{3}$} & \multicolumn{1}{c}{$\mathrm{pT}_{4}$} & \multicolumn{1}{c}{$\mathrm{pT}_{5}$} & \multicolumn{1}{c}{$\mathrm{pT}_{6}$} \\
\hline Cring1 & -22.49 & -21.79 & -21.17 & -20.67 & -20.39 & -19.52 \\
Cring2 & -30.10 & -29.59 & -29.34 & -29.05 & -28.72 & -28.46 \\
Cring3 & -27.96 & -27.78 & -27.91 & -28.17 & -28.57 & -28.57 \\
Cring4 & -14.61 & -14.64 & -14.90 & -15.34 & -15.41 & -16.00 \\
Nring1 & 13.75 & 13.45 & 13.09 & 12.89 & 12.76 & 12.45 \\
Cring5 & & -13.18 & -12.67 & -12.03 & -12.08 & -11.27 \\
Cring6 & & -24.82 & -24.71 & -24.54 & -24.48 & -24.71 \\
Cring7 & & & -24.58 & -24.63 & -24.74 & -24.70 \\
Cring8 & & & -13.31 & -13.59 & -13.79 & -14.38 \\
Nring2 & & & 13.69 & 13.67 & 13.60 & 13.77 \\
Cring9 & & & & -12.81 & -12.38 & -11.98 \\
Cring10 & & & & -24.45 & -24.31 & -24.32 \\
Cring11 & & & & & -24.44 & -24.48 \\
Cring12 & & & & & -13.03 & -13.44 \\
Nring3 & & & & & -13.73 \\
Cring13 & & & & & & -24.26 \\
Cring14 & & & & & & \\
\end{tabular}

of $\operatorname{NICS}_{z z}(1)$ increases gradually for Cring1 and reaches the most negative -19.98 for $\mathrm{pB}_{6}$. The inner Crings show significantly lower negative $\operatorname{NICS}_{z z}(1)(-6.45$ to -8.83$)$ than the terminal ones whereas compared to the terminal Nrings (18.49 to 16.51), the inner Nrings appear to be less antiaromatic (13.60 to 14.02). The positive $\operatorname{NICS}_{z z}(1)$ values of Nrings can be correlated with a $\pi$-electron count of 8 for the N-heterocycle. Like the pB series, $\mathrm{NICS}_{z z}(1)$ of pN, pA and pT series too indicates a significant

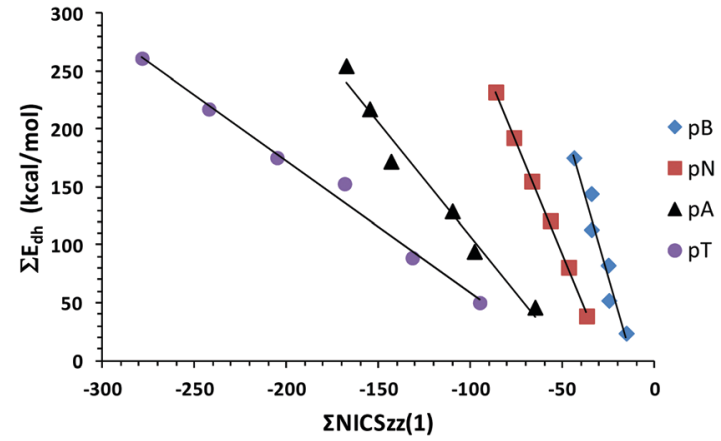

Fig. 5 Correlation between the $\Sigma \mathrm{NICS}_{z z}(1)$ index for the pB, pN, pA, and pT series of molecules and the dehydrogenation energy.

decrease in aromaticity for LPA moieties from the terminal to the inner region. Moreover, compared to $\operatorname{NICS}_{z z}(1)$ in the range 18.21 to 19.34 observed for $\mathrm{N}$-heterocycles of the $\mathrm{pN}$ series, $\operatorname{NICS}_{z z}(1)$ for the pA series shows a decrease by 3.37 to 3.65 units while that of pT series shows a decrease by 5.45 to 5.54 units (Tables 9 and 10).

A linear correlation between the total negative $\operatorname{NICS}_{z z}(1)$ value $\left(\sum \operatorname{NICS}_{z z}(1)\right)$ that represents the aromatic character of the Crings and the total dehydrogenation energy $\Sigma E_{\mathrm{dh}}$ exists for the $\mathrm{pB}, \mathrm{pN}, \mathrm{pA}$ and $\mathrm{pT}$ series of molecules (Fig. 5). The magnitude of the slope of the correlation line is the highest for the pB series and it decreases along the pN, pA and pT series indicating aromatic dilution. This correlation as well as the correlation observed between $\Sigma$ HOMA and $\Sigma E_{\text {dh }}$ in Fig. 4 clearly brings out the multidimensional character of aromaticity, viz. the underlying magnetic, structural and energetic features. Previously, Solà et al. ${ }^{85}$ noted that the NICS method has wellknown problems in dealing with some condensed benzenoid structures ${ }^{27,86-90}$ while in the case of Clar's systems analyzed here, both HOMA and $\operatorname{NICS}_{z z}(1)$ performed considerably well. ${ }^{85}$ Solà et al. also suggested that aromaticity indices based on electron delocalization concepts may perform better than both geometry and magnetic based indices of aromaticity in dealing with condensed benzenoid molecules. ${ }^{85}$

\section{Molecular electrostatic potential and electron delocalization}

Fig. 6 depicts the MESP features of benzene, naphthalene, anthracene and tetracene. The $\pi$-electron cloud of the molecules is seen in the MESP isosurface lobes and the most negative valued MESP $\left(V_{\min }\right)$ is useful for comparing the relative electron rich character of the $\pi$-regions in different molecules. $V_{\min }$ is the most negative for benzene $\left(-15.06 \mathrm{kcal} \mathrm{mol}^{-1}\right)$ and along the LPA series, it gradually decreases with the increase in the $n_{\pi}$ value. The MESP features of the LPA mimics $\mathrm{pB}_{6}, \mathrm{pN}_{6}, \mathrm{pA}_{6}$ and $\mathrm{pT}_{6}$ are depicted in Fig. 7 as representative cases. For the rest of the systems, MESP features show close similarity to the representative cases and are presented in the ESI. $\dagger$ The $V_{\min }$ observed on the LPA unit of every system is depicted in Table 11 along with the sum of all $V_{\min }$ values referred to as $\Sigma V_{\min }$. In the pB series, the N-heterocycles show $V_{\min }$ for the N-lone pair region in the range -25.73 to $-34.51 \mathrm{kcal} \mathrm{mol}^{-1}$, wherein the 


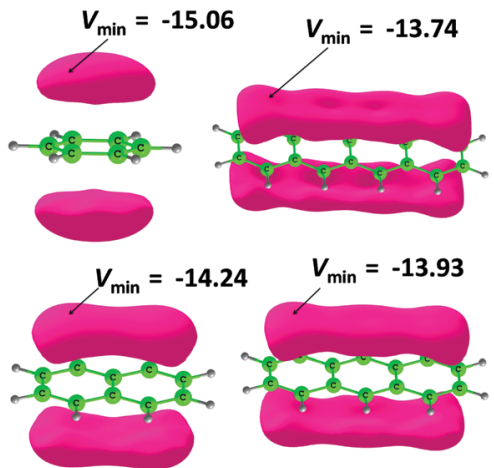

Fig. 6 Plots of the MESP isosurface $\left(-9.0 \mathrm{kcal} \mathrm{mol}^{-1}\right)$ for benzene, naphthalene, anthracene and tetracene along with the MESP minimum in $\mathrm{kcal} \mathrm{mol}^{-1}$.

innermost $\mathrm{N}$-heterocycle shows the most negative character while the outermost one shows the least negative character. However, compared to $V_{\min }$ of dihydropyrazine $\left(-46.25 \mathrm{kcal} \mathrm{mol}^{-1}\right)$, the N-lone pairs of the heterocycles are significantly less negative. This indicates minor delocalization of the $\mathrm{N}$-lone pairs in the LPA mimics which is not surprising considering the pyramidal nature of the $\mathrm{N}$-centers. In the $\mathrm{pN}$ series, $V_{\min }$ observed for the $\mathrm{N}$-heterocycles is in the range -3.14 to $-8.78 \mathrm{kcal} \mathrm{mol}^{-1}$ while the $\mathrm{pA}$ and pT series do not show $V_{\min }$ for N-heterocycles. This indicates that the $\mathrm{N}$-lone pair is strongly delocalized with the LPA units in the pN, pA and pT series of molecules and the planar configuration of N-centers substantiates this statement. The $V_{\text {min }}$ data in Table 11 clearly show that as the size of the LPA mimic increases, the negative character of $V_{\text {min }}$ on the outer most LPA unit increases gradually. This pattern is almost repeated in the interior LPA units as well. The enhancement in the negative character of $V_{\min }$ with the increase in the size of the molecule suggests the increasing participation of $\mathrm{N}$-lone pairs in $\pi$-electron delocalization. This also means that the aromaticity of the molecule increases with the increase in the length of the molecule. In fact, the $\Sigma V_{\min }$ quantity emerges as a good indicator of electron delocalization in the molecule and shows a strong linear correlation with the total dehydrogenation energy $\Sigma E_{\mathrm{dh}}$ for different series of molecules (Fig. 8). The magnitude of the slope of the correlation plot is the highest for the pT series and it decreases along the $\mathrm{pA}, \mathrm{pN}$ and $\mathrm{pB}$ series. This indicates that $\mathrm{N}$-lone pair donation to enhance the aromaticity of hydrocarbon portions is the highest for the pT series and the lowest for the pB series. The MESP isosurface features also indicate that each of the LPA unit in the LPA mimic almost retains the MESP features of the parent hydrocarbon. This may suggest that the reactivity of an LPA unit in an LPA mimic could match the reactivity of the parent hydrocarbon irrespective of the length of the molecule. Hence, the stability of the

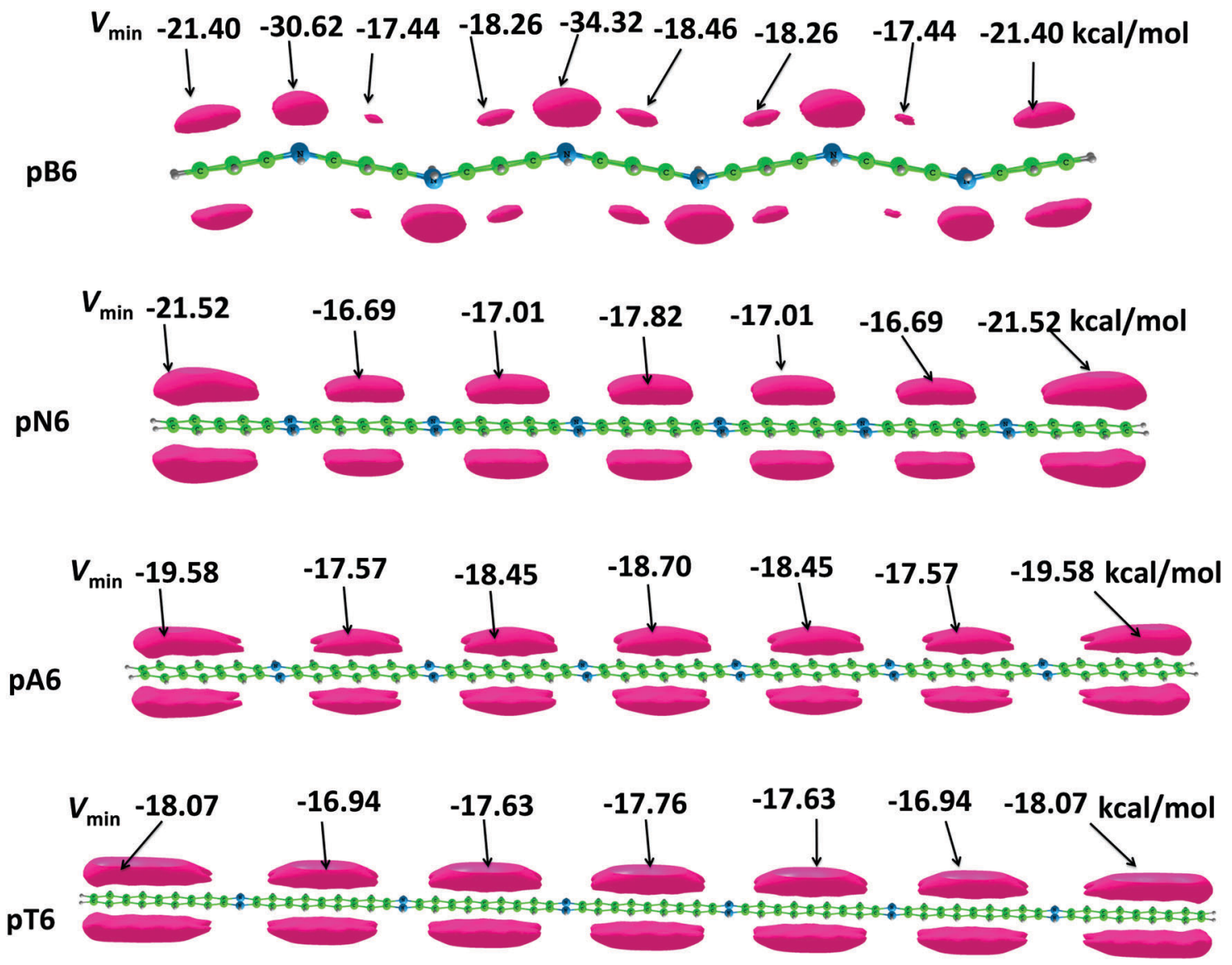

Fig. 7 Plots of the MESP isosurface $\left(-9.0 \mathrm{kcal} \mathrm{mol}^{-1}\right)$ for benzene, naphthalene, anthracene and tetracene along with the MESP minimum in $\mathrm{kcal}$ mol ${ }^{-1}$. 
Table 11 MESP minimum ( $\mathrm{kcal} \mathrm{mol}^{-1}$ ) observed on the LPA units for the $\mathrm{pB}, \mathrm{pN}, \mathrm{pA}$, and $\mathrm{pT}$ series of molecules

\begin{tabular}{|c|c|c|c|c|c|c|c|c|}
\hline \multirow[b]{2}{*}{ System } & \multicolumn{7}{|c|}{$V_{\min }$ on the LPA unit from left to right } & \multirow[b]{2}{*}{$\Sigma V_{\min }$} \\
\hline & 1 & 2 & 3 & 4 & 5 & 6 & 7 & \\
\hline $\mathrm{pB}_{1}$ & -19.0 & -19.0 & & & & & & -38.1 \\
\hline $\mathrm{pB}_{2}$ & -20.4 & -15.4 & -20.4 & & & & & -56.1 \\
\hline $\mathrm{pB}_{3}$ & -20.8 & -16.6 & -16.6 & -20.8 & & & & -74.8 \\
\hline $\mathrm{pB}_{4}$ & -21.1 & -17.1 & -17.5 & -17.1 & -21.1 & & & -93.9 \\
\hline $\mathrm{pB}_{5}$ & -21.3 & -17.3 & -18.0 & -18.0 & -17.3 & -21.3 & & -113.2 \\
\hline $\mathrm{pB}_{6}$ & -21.4 & -17.4 & -18.3 & -18.5 & -18.3 & -17.4 & -21.4 & -132.4 \\
\hline $\mathrm{pN}_{1}$ & -18.3 & -18.3 & & & & & & -36.6 \\
\hline $\mathrm{pN}_{2}$ & -20.1 & -14.4 & -20.1 & & & & & -54.6 \\
\hline $\mathrm{pN}_{3}$ & -20.8 & -15.7 & -15.7 & -20.8 & & & & -73.1 \\
\hline $\mathrm{pN}_{4}$ & -21.2 & -16.5 & -16.9 & -16.5 & -21.2 & & & -92.1 \\
\hline $\mathrm{pN}_{5}$ & -21.4 & -16.8 & -17.4 & -17.4 & -16.8 & -21.4 & & -111.2 \\
\hline $\mathrm{pN}_{6}$ & -21.5 & -17.0 & -17.8 & -18.0 & -17.8 & -17.0 & -21.5 & -130.4 \\
\hline $\mathrm{pA}_{1}$ & -17.4 & -17.4 & & & & & & -34.9 \\
\hline $\mathrm{pA}_{2}$ & -18.6 & -15.8 & -18.6 & & & & & -53.1 \\
\hline $\mathrm{pA}_{3}$ & -19.2 & -16.9 & -16.9 & -19.2 & & & & -72.2 \\
\hline $\mathrm{pA}_{4}$ & -19.3 & -17.4 & -17.9 & -17.4 & -19.3 & & & -91.3 \\
\hline $\mathrm{pA}_{5}$ & -19.6 & -17.7 & -18.4 & -18.4 & -17.7 & -19.6 & & -111.3 \\
\hline $\mathrm{pA}_{6}$ & -19.5 & -17.6 & -18.4 & -18.7 & -18.4 & -17.6 & -19.5 & -129.6 \\
\hline $\mathrm{pT}_{1}$ & -16.6 & -16.6 & & & & & & -33.1 \\
\hline $\mathrm{pT}_{2}$ & -17.4 & -15.3 & -17.4 & & & & & -50.1 \\
\hline $\mathrm{pT}_{3}$ & -17.7 & -16.3 & -16.3 & -17.7 & & & & -67.9 \\
\hline $\mathrm{pT}_{4}$ & -18.0 & -16.6 & -17.0 & -16.6 & -18.0 & & & -86.0 \\
\hline $\mathrm{pT}_{5}$ & -18.0 & -16.8 & -17.4 & -17.4 & -16.8 & -18.0 & & -104.4 \\
\hline $\mathrm{pT}_{6}$ & -18.0 & -16.9 & -17.6 & -17.7 & -17.6 & -16.9 & -18.0 & -122.7 \\
\hline
\end{tabular}

LPA mimic could largely depend on the stability of the parent hydrocarbon. In fact, considering the enhancement in the total aromaticity of the LPA mimic due to the utilization of N-lone pairs in $\pi$-conjugation, the overall stability of the system could be predicted to be higher than the parent hydrocarbon. Thus, the MESP features strongly suggest the existence of stable LPA mimics containing $\mathrm{N}$-heterocycles.

\section{Frontier molecular orbitals}

In the case of benzene, naphthalene, anthracene, and tetracene, the HOMO energy ( $\varepsilon 1)$, LUMO energy $(\varepsilon 2)$, and the HOMOLUMO energy gap $(\Delta \varepsilon)$ given as ordered triples $(\varepsilon 1, \varepsilon 2, \Delta \varepsilon)$ in $\mathrm{eV}$ is $(-6.44,-0.95,5.49),(-5.56,-1.88,3.68),(-5.04,-2.49,2.55)$ and $(-4.69,-2.89,1.80)$, respectively. A steady decrease in the

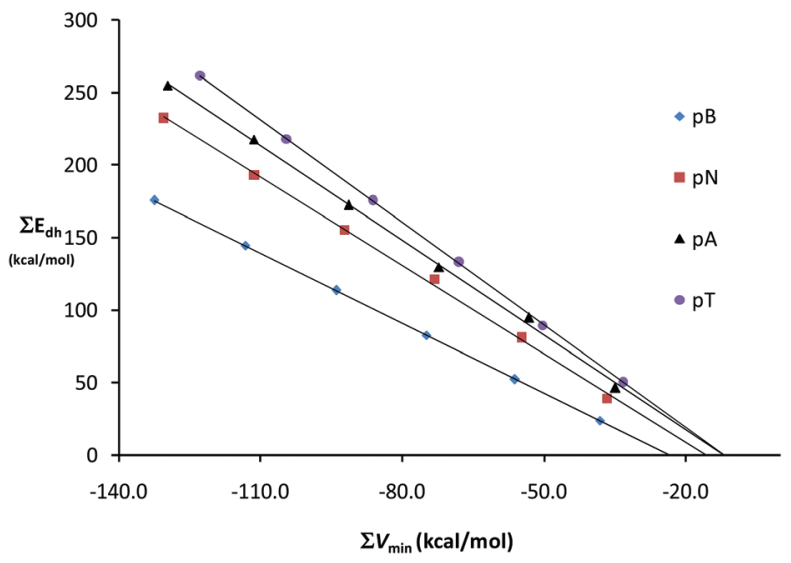

Fig. 8 Correlation between the $\Sigma V_{\min }$ index for the $p B, p N, p A$, and $p T$ series of molecules and the dehydrogenation energy.
$\Delta \varepsilon$ with respect to the size of the acene is evident and suggests that large LPA systems are attractive for HOMO-LUMO energy modulation for photonic applications and the limiting factor is the unstable character of the higher derivatives. Compared to LPA, all the corresponding LPA mimics show significantly higher $\varepsilon 1$ and slightly higher $\varepsilon 2$ (Table 12). For instance, in the case of LPA mimics composed of anthracene moieties, viz. $\mathrm{pA}_{1}-\mathrm{pA}_{6}, \varepsilon 1$ is in the range -4.55 to $-3.99 \mathrm{eV}$ which is higher than $\varepsilon 1$ of anthracene $(-5.04 \mathrm{eV})$ while their $\varepsilon 2$ falls in a narrow range -2.44 to $-2.34 \mathrm{eV}$ which is close to $\varepsilon 1-2.49 \mathrm{eV}$ observed for anthracene. The HOMO and LUMO pictures given for the representative cases $\mathrm{pA}_{2}$ and $\mathrm{pT}_{2}$ (Fig. 9) show that the HOMO is formed by the delocalization of $\mathrm{N}$-lone pairs in the $B_{1 \mathrm{~g}}$ symmetric $\pi$-orbital for the former and the $A_{\mathrm{u}}$ symmetric $\pi$-orbital for the latter (see the ESI $\dagger$ for the HOMO and the LUMO of other molecules) whereas the LUMO localized on the LPA core shows features very similar to the $B_{3 \mathrm{u}}$ symmetric LUMO of anthracene and the $B_{1 \mathrm{~g}}$ symmetric LUMO of tetracene (under $D_{2 \mathrm{~h}}$ molecular symmetry). In fact, in every molecule, two sets of $\pi$-MOs are observed, viz. one characteristic of the LPA moiety, localized exclusively on them and devoid of any contributions from the N-lone pairs and the other consisting of the contributions of N-lone pairs. The delocalization of N-lone pairs in the HOMO is observed for all the LPA mimics and the energy of the HOMO is influenced by the number of $\mathrm{N}$-centers in the molecule whereas LUMO energy is independent of the N-centers. Since only the HOMO energy showed a significant increase with respect to the length of the LPA mimic, a steady decrease in the HOMO-LUMO energy gap with the increase in the size of the molecule is observed in all the systems. In fact, on going from $\mathrm{pB}_{1}$ to $\mathrm{pT}_{6}, \mathrm{HOMO}-\mathrm{LUMO}$ energy modulation can be achieved from $3.21 \mathrm{eV}$ to $1.22 \mathrm{eV}$, which suggests that excellent band gap tuning using dihydropyrazine annulated linear polyacenes can be achieved for solar cell applications.

The computed values of NICS indices, HOMA, MESP $V_{\min }$, HOMO-LUMO gap and $E_{\mathrm{dh}}$ values at M06 and M06-2X levels are presented in the ESI $\uparrow$ for a representative case, the $\mathrm{pN}$ series of molecules. The trends in all these quantities at these two levels are found to be nearly identical to the M06L results.

Table 12 HOMO ( $\varepsilon 1)$, LUMO ( $\varepsilon 2)$ and HOMO-LUMO energy gap $(\Delta \varepsilon)$ for the $\mathrm{pB}, \mathrm{pN}, \mathrm{pA}$, and $\mathrm{pT}$ series of molecules. All values in $\mathrm{eV}$. B, N, A and T are benzene, naphthalene, anthracene, and tetracene, respectively

\begin{tabular}{llllllll}
\hline System & $\varepsilon 1$ & $\varepsilon 2$ & $\Delta \varepsilon$ & System & $\varepsilon 1$ & $\varepsilon 2$ & $\Delta \varepsilon$ \\
\hline $\mathrm{B}$ & -6.44 & -0.95 & 5.49 & $\mathrm{~A}$ & -5.04 & -2.49 & 2.55 \\
$\mathrm{pB}_{1}$ & -4.15 & -0.94 & 3.21 & $\mathrm{pA}_{1}$ & -4.55 & -2.44 & 2.11 \\
$\mathrm{pB}_{2}$ & -3.61 & -0.93 & 2.69 & $\mathrm{pA}_{2}$ & -4.34 & -2.40 & 1.93 \\
$\mathrm{pB}_{3}$ & -3.40 & -0.91 & 2.50 & $\mathrm{pA}_{3}$ & -4.17 & -2.38 & 1.80 \\
$\mathrm{pB}_{4}$ & -3.28 & -0.89 & 2.39 & $\mathrm{pA}_{4}$ & -4.08 & -2.36 & 1.73 \\
$\mathrm{pB}_{5}$ & -3.21 & -0.88 & 2.33 & $\mathrm{pA}_{5}$ & -4.02 & -2.35 & 1.68 \\
$\mathrm{pB}_{6}$ & -3.17 & -0.87 & 2.30 & $\mathrm{pA}_{6}$ & -3.99 & -2.34 & 1.65 \\
$\mathrm{~N}$ & -5.56 & -1.88 & 3.68 & $\mathrm{~T}$ & -4.69 & -2.89 & 1.80 \\
$\mathrm{pN}_{1}$ & -4.43 & -1.81 & 2.62 & $\mathrm{pT}_{1}$ & -4.32 & -2.84 & 1.47 \\
$\mathrm{pN}_{2}$ & -3.96 & -1.77 & 2.19 & $\mathrm{pT}_{2}$ & -4.16 & -2.81 & 1.35 \\
$\mathrm{pN}_{3}$ & -3.75 & -1.74 & 2.01 & $\mathrm{pT}_{3}$ & -4.08 & -2.79 & 1.29 \\
$\mathrm{pN}_{4}$ & -3.62 & -1.71 & 1.92 & $\mathrm{pT}_{4}$ & -4.03 & -2.77 & 1.26 \\
$\mathrm{pN}_{5}$ & -3.55 & -1.69 & 1.86 & $\mathrm{pT}_{5}$ & -4.00 & -2.76 & 1.24 \\
$\mathrm{pN}_{6}$ & -3.49 & -1.67 & 1.82 & $\mathrm{pT}_{6}$ & -3.98 & -2.75 & 1.22
\end{tabular}




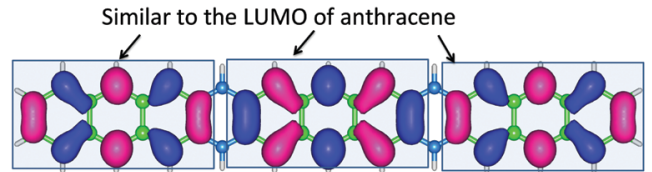

LUMO of pA2

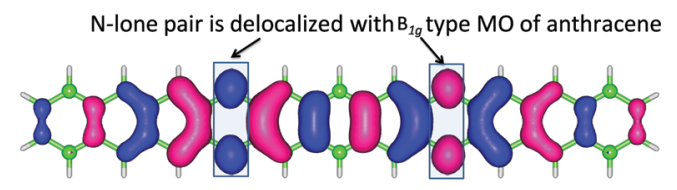

HOMO of pA2

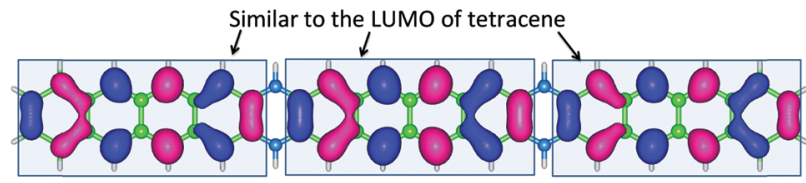

LUMO of pT2

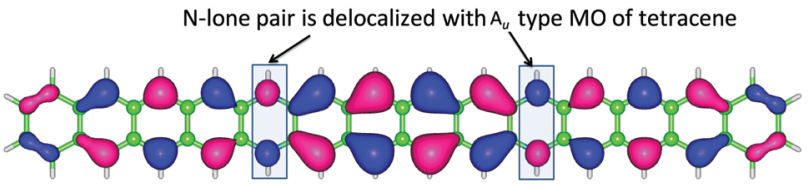

HOMO of pT2

Fig. $9 \mathrm{HOMO}$ and LUMO orbitals of $\mathrm{pA}_{2}$ and $\mathrm{pT}_{2}$.

Furthermore, the linear correlations that we discussed in this study, viz. $\Sigma$ HOMA versus $\Sigma E_{\mathrm{dh}}, \Sigma \mathrm{NICS}_{z z}(1)$ versus $\Sigma E_{\mathrm{dh}}$ and $\Sigma V_{\min }$ versus $\Sigma E_{\mathrm{dh}}$, are all found to be true for both these methods.

\section{Conclusions}

Density functional theory calculations at the M06L/6-311++G(d,p) level have been carried out on 24 dihydropyrazine annulated linear polyacene systems to study their aromaticity and HOMOLUMO energy gap. The LPA mimics composed of benzene units $\left(\mathrm{pB}_{1}-\mathrm{pB}_{6}\right)$ are non-planar while those composed of naphthalene $\left(\mathrm{pN}_{1}-\mathrm{pN}_{6}\right)$, anthracene $\left(\mathrm{pA}_{1}-\mathrm{pA}_{6}\right)$ and tetracene $\left(\mathrm{pT}_{1}-\mathrm{pT}_{6}\right)$ units are planar. In the $\mathrm{pB}$ series, mixing of $\mathrm{N}$-lone pairs with the $\pi$-system of the benzene core is ineffective due to the core retaining six- $\pi$ electron delocalization while the decrease in the net $\pi$-electron content of the higher acene cores promotes strong delocalization of $\mathrm{N}$-lone pairs with the $\pi$-electrons of carbons rings, leading to planar structures. All the molecules showed strong multidimensional character of aromaticity such as energetic stabilization, bond length equalization, and magnetic properties. The dehydrogenation energy $\left(E_{\mathrm{dh}}\right)$ computed for each of the N-heterocycles of an LPA mimic provided a simple and effective way to assess the thermodynamic stability of the molecule due to aromaticity. Aromatic stabilization is enhanced in larger LPA mimics due to enhancement in the involvement of $\mathrm{N}$-lone pairs in $\pi$-electron conjugation. This has been verified by the analysis of molecular electrostatic potential (MESP) features as this property showed improvements in the electron rich character of the core hydrocarbon units at the expense of N-lone pairs.
Molecular orbital (MO) features also showed the mixing of $\mathrm{N}$-lone pair orbitals with the $\pi$-systems of the hydrocarbon core. This mixing led to significant modification of the HOMO of the LPA unit and an increase in its energy, while the LUMO retained properties and energy close to those of the LPA unit. In other words, dihydropyrazine annulations led to a decrease in the HOMO-LUMO energy gap. Overall, MESP and MO features indicated that the reactivity of the hydrocarbon portion of the LPA mimics should be similar to that of the parent LPA unit. In fact, considering the enhancement in the aromatic character of the LPA unit, the reactivity of the LPA mimic can be predicted to be weaker than the parent LPA system.

The dihydropyrazine systems $\mathrm{pB}_{1}{ }^{67,91}$ and $\mathrm{pN}_{1}{ }^{57}$ are known in the literature while higher analogues or higher acene based systems are yet to be synthesised. As mentioned before, the benzene core could be unattractive for making planar structures while for higher acenes such as tetracene, even one annulation of the N-heterocycle can yield a planar, aromatic structure with nine rings. We hope that the theoretical predictions provided in this work may inspire synthetic chemists to explore the rich possibilities of higher LPA mimics, including the derivatization of the N-centres for improving solubility requirements.

\section{Acknowledgements}

This research work was supported by CSIR, India through the project CSC0129 and R. R. is thankful to UGC, India for providing a research fellowship. The generous computational time provided by CSIR-4PI, Bengaluru is gratefully acknowledged.

\section{References}

1 R. Firouzi and M. Zahedi, THEOCHEM, 2008, 862, 7.

2 J. E. Anthony, Chem. Rev., 2006, 106, 5028.

3 T. Yamabe, S. Yata and S. Wang, Synth. Met., 2003, 137, 949.

4 T. Strassner, A. Weitz, J. Rose, F. Wudl and K. N. Houk, Chem. Phys. Lett., 2000, 321, 459.

5 J. E. Anthony, Angew. Chem., Int. Ed., 2008, 47, 452.

6 G. Brocks, J. van den Brink and A. F. Morpurgo, Phys. Rev. Lett., 2004, 93, 146405.

7 W.-Q. Deng and W. A. Goddard, J. Phys. Chem. A, 2004, 108, 8614.

8 Y. C. Cheng, R. J. Silbey, D. A. da Silva Filho, J. P. Calbert, J. Cornil and J. L. Brédas, J. Chem. Phys., 2003, 118, 3764.

9 D. Biermann and W. Schmidt, J. Am. Chem. Soc., 1980, $102,3163$.

10 C. Tönshoff and H. F. Bettinger, Angew. Chem., Int. Ed., 2010, 49, 4125.

11 R. Mondal, B. K. Shah and D. C. Neckers, J. Am. Chem. Soc., 2006, 128, 9612.

12 E. Clar, Polycyclic hydrocarbons, Academic Press, London, 1964, vol. 1 \& 2 .

13 E. Clar, The aromatic sextet, J. Wiley, London, New York, 1972.

14 M. Solà, Front. Chem., 2013, 1, 22, DOI: 10.3389/fchem.2013.00022.

15 M. Randić, Chem. Rev., 2003, 103, 3449. 
16 K. P. Vijayalakshmi and C. H. Suresh, New J. Chem., 2010, 34, 2132.

17 S. R. Gadre and R. N. Shirsat, Electrostatics of Atoms and Molecules, Univesities Press, Hyderabad, 2000.

18 P. Bultinck, M. Rafat, R. Ponec, B. Van Gheluwe, R. CarbóDorca and P. Popelier, J. Phys. Chem. A, 2006, 110, 7642.

19 A. R. Katritzky, K. Jug and D. C. Oniciu, Chem. Rev., 2001, 101, 1421.

20 F. Feixas, E. Matito, J. Poater and M. Solà, Chem. Soc. Rev., 2015, 44, 6434.

21 S. K. Pandey, D. Manogaran, S. Manogaran and H. F. Schaefer, J. Phys. Chem. A, 2016, 120, 2894.

22 K. Jug and A. M. Köster, J. Phys. Org. Chem., 1991, 4, 163.

23 A. R. Katritzky, P. Barczynski, G. Musumarra, D. Pisano and M. Szafran, J. Am. Chem. Soc., 1989, 111, 7.

24 M. K. Cyrañski, T. M. Krygowski, A. R. Katritzky and P. v. R. Schleyer, J. Org. Chem., 2002, 67, 1333.

25 M. Alonso and B. Herradón, Chem. - Eur. J., 2007, 13, 3913.

26 A. Stanger, Chem. Commun., 2009, 1939.

27 P. Lazzeretti, Phys. Chem. Chem. Phys., 2004, 6, 217.

28 S. Motomura, M. Nakano, H. Fukui, K. Yoneda, T. Kubo, R. Carion and B. Champagne, Phys. Chem. Chem. Phys., 2011, 13, 20575.

29 M. Kaipio, M. Patzschke, H. Fliegl, F. Pichierri and D. Sundholm, J. Phys. Chem. A, 2012, 116, 10257.

30 G. Monaco and R. Zanasi, J. Phys. Chem. A, 2014, 118, 1673. 31 P. O. Dral, M. Kivala and T. Clark, J. Org. Chem., 2013, 78, 1894. 32 M. Winkler and K. N. Houk, J. Am. Chem. Soc., 2007, 129, 1805.

33 A. L. Appleton, S. M. Brombosz, S. Barlow, J. S. Sears, J.-L. Bredas, S. R. Marder and U. H. F. Bunz, Nat. Commun., 2010, 1, 91.

34 Q. Miao, Synlett, 2012, 326.

35 O. Tverskoy, F. Rominger, A. Peters, H.-J. Himmel and U. H. F. Bunz, Angew. Chem., Int. Ed., 2011, 50, 3557.

36 J. U. Engelhart, B. D. Lindner, O. Tverskoy, F. Rominger and U. H. F. Bunz, Org. Lett., 2012, 14, 1008.

37 B. D. Lindner, J. U. Engelhart, M. Märken, O. Tverskoy, A. L. Appleton, F. Rominger, K. I. Hardcastle, M. Enders and U. H. F. Bunz, Chem. - Eur. J., 2012, 18, 4627.

38 U. H. F. Bunz and J. U. Engelhart, Chem. - Eur. J., 2016, 22, 4680 .

39 C.-L. Song, C.-B. Ma, F. Yang, W.-J. Zeng, H.-L. Zhang and X. Gong, Org. Lett., 2011, 15, 2880.

40 K. Goto, R. Yamaguchi, S. Hiroto, H. Ueno, T. Kawai and H. Shinokubo, Angew. Chem., Int. Ed., 2012, 51, 10333.

41 K. Seth, S. Raha Roy and A. K. Chakraborti, Chem. Commun., 2016, 52, 922.

42 J. K. Laha, K. S. S. Tummalapalli and A. Gupta, Org. Lett., 2014, 16, 4392.

43 Z. Wróbel, K. Stachowska and A. Kwast, Eur. J. Org. Chem., 2014, 7721.

44 L. Yu, X. Zhou, D. Wu and H. Xiang, J. Organomet. Chem., 2012, 705, 75.

45 F. Wudl, P. A. Koutentis, A. Weitz, B. Ma, T. Strassner, K. N. Houk and S. I. Khan, Pure Appl. Chem., 1999, 71, 295.
46 M. Altarawneh and B. Z. Dlugogorski, Environ. Sci. Technol., 2015, 49, 2215.

47 O. Hinsberg, Liebigs Ann., 1901, 319, 257.

48 G. R. Clemo and H. McIlwain, J. Chem. Soc., 1934, 1991.

49 U. H. F. Bunz, Chem. - Eur. J., 2009, 15, 6780.

50 H. Alvaro Galué, O. Pirali and J. Oomens, Astron. Astrophys., 2010, 517, A15.

51 Q. Miao, T.-Q. Nguyen, T. Someya, G. B. Blanchet and C. Nuckolls, J. Am. Chem. Soc., 2003, 125, 10284.

52 Q. Miao, Adv. Mater., 2014, 26, 5541.

53 K. E. Maly, Cryst. Growth Des., 2011, 11, 5628.

54 Y. Ma, Y. Sun, Y. Liu, J. Gao, S. Chen, X. Sun, W. Qiu, G. Yu, G. Cui, W. Hu and D. Zhu, J. Mater. Chem., 2005, 15, 4894.

55 C. An, X. Guo and M. Baumgarten, Cryst. Growth Des., 2015, 15, 5240.

56 A. H. Endres, M. Schaffroth, F. Paulus, H. Reiss, H. Wadepohl, F. Rominger, R. Krämer and U. H. F. Bunz, J. Am. Chem. Soc., 2016, 138, 1792.

57 Q. Tang, D. Zhang, S. Wang, N. Ke, J. Xu, J. C. Yu and Q. Miao, Chem. Mater., 2009, 21, 1400.

58 S.-Z. Weng, P. Shukla, M.-Y. Kuo, Y.-C. Chang, H.-S. Sheu, I. Chao and Y.-T. Tao, ACS Appl. Mater. Interfaces, 2009, 1, 2071.

59 M. M. Islam, S. Pola and Y.-T. Tao, Chem. Commun., 2011, 47, 6356.

60 X. Wang and K.-C. Lau, J. Phys. Chem. C, 2012, 116, 22749.

61 C. Li, W. Jiang, X. Zhu and Z. Wang, Asian J. Org. Chem., 2014, 3, 114.

62 M. Karim and Y. Jahng, Molecules, 2016, 21, 407.

63 G. Westphal, Z. Phys. Chem., 1969, 9, 339.

64 S.-J. Chen and F. W. Fowler, J. Org. Chem., 1970, 35, 3987.

65 G. B. Schuster, S. P. Schmidt and B. G. Dixon, J. Phys. Chem., 1980, 84, 1841.

66 F. W. Fowler and S.-J. Chen, J. Org. Chem., 1971, 36, 4025.

67 K. V. Subba Rao, B. Srinivas, A. R. Prasad and M. Subrahmanyam, Chem. Commun., 2000, 1533.

68 K. Oshima, T. Ohmura and M. Suginome, Chem. Commun., 2012, 48, 8571.

69 R. R. Schmidt, M. Dimmler and P. Hemmerich, Ber., 1976, 109, 2395.

70 M. Märken, B. D. Lindner, A. L. Appleton, F. Rominger and U. H. F. Bunz, Pure Appl. Chem., 2014, 86, 483.

71 H. Choi, X. Yang, G. W. Mitchell, C. P. Collier, F. Wudl and J. R. Heath, J. Phys. Chem. B, 2002, 106, 1833.

72 J. U. Engelhart, F. Paulus, M. Schaffroth, V. Vasilenko, O. Tverskoy, F. Rominger and U. H. F. Bunz, J. Org. Chem., 2016, 81, 1198.

73 Y. Zhao and D. G. Truhlar, Theor. Chem. Acc., 2008, 120, 215. 74 Y. Zhao and D. G. Truhlar, Acc. Chem. Res., 2008, 41, 157.

75 M. J. Frisch, G. W. Trucks, H. B. Schlegel, G. E. Scuseria, M. A. Robb, J. R. Cheeseman, G. Scalmani, V. Barone, B. Mennucci, G. A. Petersson, H. Nakatsuji, M. Caricato, X. Li, H. P. Hratchian, A. F. Izmaylov, J. Bloino, G. Zheng, J. L. Sonnenberg, M. Hada, M. Ehara, K. Toyota, R. Fukuda, J. Hasegawa, M. Ishida, T. Nakajima, Y. Honda, O. Kitao, H. Nakai, T. Vreven, J. A. Montgomery Jr., J. E. Peralta, F. Ogliaro, M. J. Bearpark, J. Heyd, E. N. Brothers, K. N. Kudin, 
V. N. Staroverov, R. Kobayashi, J. Normand, K. Raghavachari, A. P. Rendell, J. C. Burant, S. S. Iyengar, J. Tomasi, M. Cossi, N. Rega, N. J. Millam, M. Klene, J. E. Knox, J. B. Cross, V. Bakken, C. Adamo, J. Jaramillo, R. Gomperts, R. E. Stratmann, O. Yazyev, A. J. Austin, R. Cammi, C. Pomelli, J. W. Ochterski, R. L. Martin, K. Morokuma, V. G. Zakrzewski, G. A. Voth, P. Salvador, J. J. Dannenberg, S. Dapprich, A. D. Daniels, Ö. Farkas, J. B. Foresman, J. V. Ortiz, J. Cioslowski and D. J. Fox, Gaussian, Inc., Wallingford, CT, USA, 2009.

76 P. v. R. Schleyer, C. Maerker, A. Dransfeld, H. Jiao and N. J. R. v. E. Hommes, J. Am. Chem. Soc., 1996, 118, 6317.

77 J. Kruszewski and T. M. Krygowski, Tetrahedron Lett., 1972, 13, 3839.

78 K. Remya and C. H. Suresh, J. Comput. Chem., 2013, 34, 1341.

79 K. Remya and C. H. Suresh, Phys. Chem. Chem. Phys., 2015, 17, 27035.

80 K. Remya and C. H. Suresh, RSC Adv., 2016, 6, 44261.

81 T. D. Della and C. H. Suresh, Phys. Chem. Chem. Phys., 2016, 18, 14588.
82 U. H. F. Bunz, Acc. Chem. Res., 2015, 48, 1676.

83 T. M. Krygowski, H. Szatylowicz, O. A. Stasyuk, J. Dominikowska and M. Palusiak, Chem. Rev., 2014, 114, 6383.

84 Z. Chen, C. S. Wannere, C. Corminboeuf, R. Puchta and P. v. R. Schleyer, Chem. Rev., 2005, 105, 3842.

85 F. Feixas, E. Matito, J. Poater and M. Solà, J. Comput. Chem., 2008, 29, 1543.

86 G. Portella, J. Poater, J. M. Bofill, P. Alemany and M. Solà, J. Org. Chem., 2005, 70, 2509.

87 G. Portella, J. Poater, J. M. Bofill, P. Alemany and M. Solà, J. Org. Chem., 2005, 70, 4560.

88 J. Poater, M. Solà, R. G. Viglione and R. Zanasi, J. Org. Chem., 2004, 69, 7537.

89 J. Poater, J. M. Bofill, P. Alemany and M. Solà, J. Org. Chem., 2006, 71, 1700.

90 S. Osuna, J. Poater, J. M. Bofill, P. Alemany and M. Solà, Chem. Phys. Lett., 2006, 428, 191.

91 M. G. Voronkov, É. N. Deryagina and É. N. Sukhomazova, Chem. Heterocycl. Compd., 1977, 13, 217. 